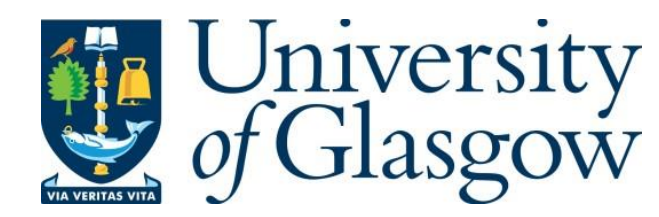

Kumar, U. and Paul, M. C. (2019) CFD modelling of biomass gasification with a volatile break-up approach. Chemical Engineering Science, 195, pp. 413-

422. (doi:10.1016/j.ces.2018.09.038)

There may be differences between this version and the published version. You are advised to consult the publisher's version if you wish to cite from it.

http://eprints.gla.ac.uk/169588/

Deposited on: 25 September 2018

Enlighten - Research publications by members of the University of Glasgow http://eprints.gla.ac.uk 


\title{
CFD modelling of biomass gasification with a volatile break- up approach
}

\author{
Umesh Kumar and Manosh C. Paul*
}

Systems, Power \& Energy Research Division, School of Engineering, University of Glasgow

Glasgow G12 8QQ, UK

\begin{abstract}
Gasification thermochemical processes of biomass in a $20 \mathrm{~kW}$ downdraft gasifier are investigated using a robust two-dimensional (2D) computational fluid dynamics (CFD) modelling method. The model includes all the four zones of the gasifier namely drying, pyrolysis, oxidation and reduction. A step-by-step approach is proposed to evaluate the composition of different gas species as a result of the volatile break-up during gasification. However, selecting suitable chemical reactions for the CFD modelling becomes challenging as the commonly used reactions in kinetic study showed discrepancy in predicting the synthesis gas compositions. A revised set of chemical mechanisms is therefore proposed in the study and the robustness of the approach is examined with results validated against data from literature. The study reports how the air equivalence ratio (ER) affects the gasifier temperature and also the composition of producer gases. The model is then applied to investigate the syngas production of various biomass feedstocks sourced from Scottish agricultural sites.
\end{abstract}

Keywords: Downdraft gasifier; Biomass gasification; CFD modelling; DPM model

"Corresponding author. Tel.: +44(0) 1413308466

E-mail address: Manosh.Paul@glasgow.ac.uk 


\section{Introduction}

An affordable, reliable and clean energy supply is one of the major challenges currently faced by the modern world. Along with the world population growth, the demand of energy is increasing day by day and in fact, every nation in the world is looking for a new and alternative source of energy. Though, biomass energy is playing a promising role to that, gasification technology able to convert biomass efficiently to valuable gases is a vital need. In gasification, various forms of biomass such as forestry residues, agricultural waste (rice husk, crops, corn), rubber wood, pine sawdust etc., could be potentially used for the generation of sustainable and renewable power and heat. However, as understood, biomass gasification is a complex thermo-chemical process by which biomass converts into synthesis gas (syngas) / producer gases through a set of homogeneous and heterogeneous reactive routes. The producer gases usually contain $\mathrm{CO}, \mathrm{H}_{2}, \mathrm{CH}_{4}, \mathrm{~N}_{2}$, and also other form of undesired pollutants such as $\mathrm{CO}_{2}$ and tar depending on the gasification process efficiency. The syngas can then be used as fuel in downstream applications e.g. in internal combustion and gas turbine engines, and fuel cell.

Numerous amount of modelling work are available in the literature which focused on the downdraft type gasifier on a different level of accuracy and modelling depth. For example, an equilibrium model (also known as a OD model) of gasification, widely used by various researchers [1-5], lacks in clear understanding of the interface between the gas and solid phase reactions during gasification, and also of the temperature and concentration profiles inside a gasifier. On the other hand, a kinetic model, implemented in [6-8], though accounted the reaction kinetics and temperature of gasifier, still lacks in comprehensive understanding of the biomass gasification process. Furthermore, this model is unable to investigate the effects of varying operating and design parameters on the production of synthesis gas. Therefore, it is understood that an advanced CFD based model might play a crucial role in the further development of this research field and also be useful for better understanding of the fundamental aspects of biomass gasification process and its design conditions. However, very few CFD models are available in the existing literatures, and most of the studies reported in the literatures have only been on the CFD simulation of an entrained gasifier [9]. A two dimensional axisymmetric CFD model was though developed for a downdraft gasifier, only the oxidation zone was considered [10]. A three dimensional (3D) CFD model was investigated for Co-firing of palm kernel shell (PKS) in a pulverized coal power plant [11]. 
Furthermore, in the literatures, many other authors [12-15] also used different chemical kinetics for the kinetic model, but a CFD based model still lacks in clear understanding of the best-suited chemical kinetics for gasification modelling. In addition, a huge variation was found in the frequency factor and activation energy of the chemical reactions [12] - thus causing a significant level of uncertainty in the selection of the reaction kinetics parameters. While some authors [16-18] investigated the effects of having difference in the chemical kinetics, they especially focused their work on the combustion of $\mathrm{CO}$ and methane.

In this study, additional chemical reactions compared to the previous study [13] are included with an aim to make the CFD model robust enough for predicting the biomass gasification processes. These reactions also include the temperature exponent for the partial oxidation, Boudouard, methanation and water gas shift reactions - the effect of which was not studied in any previously published work, to the best of the authors' knowledge. Further, the effects of reactor temperature on the gasifier height at different equivalence ratio as well as on the synthesis gas production are investigated in this study.

Additionally, the distribution of gas composition inside the gasifier is predicted and thoroughly investigated. After the drying process, volatile matter decomposition starts due to the heat supply from the oxidation zone. The volatile decomposition is an important stage in gasification because at this stage, biomass releases gaseous, char and small amount of hydrocarbons. Therefore, the concentration of volatile along the gasifier height is another important part of gasification which is also investigated in this study. To calculate the volatile decomposition from biomass, a volatile break-up approach $[19,20]$ is used. In this scheme the mass of each of the elements as well as the overall heat in the solid fuel during the process conserves. To calculate the volatile species release from the biomass, each element $(\mathrm{C}, \mathrm{H}, \mathrm{O}, \mathrm{N}, \mathrm{S})$ mass is balanced and volatile break-up scheme is generated. Furthermore, the rates of the homogenous and heterogeneous reactions along the gasifier height are investigated to identify the reactions dominating in each gasifier zone.

\section{Gasifier: model geometry and design}

A schematic diagram of the downdraft gasifier containing the various zones (drying, pyrolysis, oxidation/combustion and reduction) is shown in Fig. 1. As also shown in the figure that the air, as a gasification agent, is injected through the air nozzles to the combustion zone, while biomass is fed from the top of the gasifier. Further details on the gasifier design parameters are available in [21, 22]. 


\section{Model description}

The governing transport equations include the mass conservation, momentum transfer, energy and species concentrations which are solved numerically under the steady-state and turbulent flow condition with a set of finite rate reaction kinetics [23].

The mass conservation equation:

$$
\frac{\partial \rho}{\partial t}+\frac{\partial\left(\rho u_{i}\right)}{\partial x_{i}}=S_{i}
$$

Momentum conservation equation:

$$
\frac{\partial\left(\rho u_{i}\right)}{\partial t}+\frac{\partial\left(\rho u_{i} u_{j}\right)}{\partial x_{j}}=-\frac{\partial p}{\partial x_{i}}+\frac{\partial \tau_{i j}}{\partial x_{j}}+\rho g_{i}+F_{i}
$$

The stress tensor $\tau_{i j}$ is given by

$$
\tau_{i j}=\mu\left[\left(\frac{\partial u_{i}}{\partial x_{j}}+\frac{\partial u_{j}}{\partial x_{i}}\right)-\frac{2}{3} \nabla \cdot u_{i j} I\right]
$$

The second term on the right hand side in equation (3) is the effect of any volume dilation.

A Reynolds time-averaging technique is employed to first derive the Reynolds averaged Navier-Stokes (RANS) form of equations from (1)-(3). The additional Reynolds stresses introduced in those equations are then modelled through the Boussinesq hypothesis depending strongly on the turbulence kinetic energy, $k$, and its rate of dissipation, $\epsilon$, which are obtained from the following transport equations (standard $k-\epsilon$ model):

$$
\begin{aligned}
& \frac{\partial}{\partial x_{i}}\left(\rho k u_{i}\right)=\frac{\partial}{\partial x_{j}}\left[\left(\mu+\frac{\mu_{t}}{\sigma_{k}}\right) \frac{\partial k}{\partial x_{j}}\right]+G_{k}+G_{b}-\rho \varepsilon-Y_{M}+S_{k} \\
& \frac{\partial}{\partial x_{i}}\left(\rho \varepsilon u_{i}\right)=\frac{\partial}{\partial x_{j}}\left[\left(\mu+\frac{\mu_{t}}{\sigma_{\varepsilon}}\right) \frac{\partial \varepsilon}{\partial x_{j}}\right]+C_{1 \varepsilon} \frac{\varepsilon}{k}\left(G_{k}+C_{3 \varepsilon} G_{b}\right)-C_{2 \varepsilon} \rho \frac{\varepsilon^{2}}{k}+S_{\varepsilon}
\end{aligned}
$$

Model parameters used are $C_{1 \epsilon}=1.44 ; C_{2 \epsilon}=1.92 ; \sigma_{k}=1.0 ; \sigma_{\epsilon}=1.3[23]$.

The species transport equation is described as

$$
\frac{\partial}{\partial t}\left(\rho Y_{i}\right)+\nabla \cdot\left(\rho \vec{u} Y_{i}\right)=-\nabla \cdot \vec{J}_{i}+R_{i}+S_{i}
$$

The diffusion flux for turbulent flow is given in the following form.

$$
\overrightarrow{J_{l}}=-\left(\rho D_{i, m}+\frac{\mu_{t}}{S c_{t}}\right) \nabla Y_{i}-D_{T, i} \frac{\nabla T}{T}
$$


$S c_{t}=\frac{\mu_{t}}{\rho D_{t}}$

In addition, the flow of biomass particles is modelled by a Lagrangian approach namely discrete phase model (DPM). The model considers the trajectory of a particle through the continuous phase of fluid, while their interaction is accounted by considering the heat and mass losses of the particles as the source term in the governing equations. The trajectory of a discrete phase particle is written in a Lagrangian reference frame by integrating the force balance on the particle. This force balance equates the particle inertia with the forces acting on the particle as described below:

Force balance:

$\frac{\partial \overrightarrow{u_{p}}}{\partial t}=F_{D}\left(\vec{u}-\vec{u}_{p}\right)+\frac{\vec{g}\left(\rho_{p}-\rho\right)}{\rho_{p}}$,

where $F_{D}\left(\vec{u}-\overrightarrow{u_{p}}\right)$ is the drag force per unit particle mass and

$$
\begin{aligned}
F_{D} & =\frac{18 \mu C_{D} \operatorname{Re}}{24 \rho_{p} d_{p}{ }^{2}} . \\
R e & =\frac{\rho d_{p}\left|u_{p}-u\right|}{\mu}
\end{aligned}
$$

The temperature of particle $T_{p}$, convective heat transfer, and the absorption/emission of radiation of the particle surface are related by the following equation.

$$
m_{p} c_{p} \frac{d T_{p}}{d t}=h A_{p}\left(T-T_{p}\right)+\varepsilon_{p} A_{p} \sigma\left(T_{R}^{4}-T_{p}^{4}\right)
$$

The kinetic devolatilization rate expression for the two competing rates (Kobayashi) model is as given by the following equation:

$$
\frac{m_{v}(t)}{\left(1-f_{w, 0}\right) m_{p, 0}-m_{a}}=\int_{0}^{t}\left(\alpha_{1} R_{1}-\alpha_{2} R_{2}\right) \exp \left(-\int_{0}^{t}\left(R_{1}-R_{2}\right) d t\right) d t,
$$

where

Heat transfer during the devolatilization process:

$$
m_{p} c_{p} \frac{d T_{p}}{d t}=h A_{p}\left(T-T_{p}\right)+\frac{d m_{p}}{d t} h_{f g}+\varepsilon_{p} A_{p} \sigma\left(T_{R}{ }^{4}-T_{p}{ }^{4}\right)
$$

Heat transfer during the char combustion process:

$$
m_{p} c_{p} \frac{d T_{p}}{d t}=h A_{p}\left(T-T_{p}\right)+f_{h} \frac{d m_{p}}{d t} H_{\text {reac }}+\varepsilon_{p} A_{p} \sigma\left(T_{R}{ }^{4}-T_{p}{ }^{4}\right)
$$




\subsection{Reaction kinetics and volatile break-up method}

Biomass particles which enter the gasifier top undergo heating and consequently, the heat flowing around the biomass particles triggers a number of physical and chemical reactions. The thermochemical reactions for the oxidation and reduction zones of the gasifier used in the kinetic model are given in Table 1. However, the volatile, char and ash composition released from the biomass decomposition are expressed by the following equation.

$$
\begin{aligned}
& \text { Biomass } \rightarrow \text { Volatile }+ \text { char }+ \text { ash }+ \text { tar } \\
& \text { Volatile } \rightarrow X_{1} \mathrm{CO}+X_{2} \mathrm{H}_{2}+X_{3} \mathrm{CO}_{2}+\mathrm{X}_{4} \mathrm{CH}_{4}+\mathrm{X}_{5} \mathrm{H}_{2} \mathrm{O} \\
& \sum_{i} X_{i}=1
\end{aligned}
$$

The volatile break-up approach developed methodology shown in Fig. 2. This methodology assumes that the volatile releasing from biomass consists of carbon, oxygen, hydrogen, sulphur and nitrogen. Which are initially converted to a pseudo gas phase species, referred to as volatile, using the devolatilization model.

The gas phase volatile break-up reaction (17) was added to convert this gaseous volatile to several other gas phase species. The stoichiometric coefficients $\left(X_{1}, X_{2}, X_{3}, X_{4}\right.$ and $\left.X_{5}\right)$ for the resultant species were calculated from the obtained mass fractions and molecular weights of these species $[13,14]$.

Using the current approach, a subroutine script was written in $\mathrm{C}++$ to automatically calculate the stoichiometric coefficients of the volatile break-up reaction which were then integrated with the gasification simulation performed on ANSYS FLUENT v15 [23].

\subsection{Boundary conditions}

The first feedstock examined is rubber wood and the boundary conditions for the simulation set up are taken from the kinetic model [21, 22]. Namely, the mass flow rate of rubber wood is $3.65 \mathrm{~kg} / \mathrm{hr}$. The initial temperature of rubber wood and air are at $300 \mathrm{~K}$ and $600 \mathrm{~K}$ respectively. Air is supplied from the four nozzles located at the middle of the gasifier. Each air nozzle diameter is considered to be $0.823 \mathrm{~cm}$. The boundary condition at the gasifier outlet adopts the pressure outlet thus giving the zero gauge pressure. The air mass flow rate is varied from $3.75 \mathrm{~kg} / \mathrm{hr}$ to $6.90 \mathrm{~kg} / \mathrm{hr}$ to control the air equivalence ratio from 0.35 to 0.60 . The ultimate and proximate analyses data of rubber wood are given in Table 2. 


\subsection{Simulation setup}

Simulations of the conservation equations of two phases have been carried out using an implicit finite volume method. A pressure-velocity coupling algorithm was used to solve these governing equations in association with the boundary conditions described in the section above (ANSYS FLUENT v15 [23]). In this coupled scheme, the spatial discretization pressure was solved by a method called PRESTO with a second order upwind scheme for the momentum equations. While, the first order upwind scheme was used to solve the convection and diffusion fluxes. For getting the stable solutions, the relaxation factors have been adjusted and the residuals for all the variables converged to $10^{-3}$ but for the energy and radiation equations to $10^{-6}$. Biomass particles enter the computational domain through the mass inlet boundary condition and the total number of particles tracked depends on the number of tries under the turbulent dispersion [23]. In this model, the number of tries value was set as 10 while the number of continuous phase iterations per DPM iteration set as 40 . The particles were tracked cell by cell through the volume and subjected to the devolatilization, gasification and exchange of heat and mass with the gas phase.

\section{Results and discussion}

Initially a CFD model is established according to the above simulation setup. The developed CFD model has been validated with the kinetic model developed in [21, 22] as well as with the experiment results in [15]. Kinetic case study is then carried out to improve the prediction capability of the biomass gasification process. Further, this study is emphasised on the effect of operating variables such as the gasifier temperature and equivalence ratio on the gas composition ( $\mathrm{CO}, \mathrm{CH}_{4}, \mathrm{CO}_{2}, \mathrm{H}_{2}, \mathrm{~N}_{2}$ ) sampled at the outlet. Furthermore, the gas species distribution within the gasifier and the effect of different Scottish agricultural feedstocks on the synthesis gas composition are also studied.

\subsection{Grid independence test}

A grid dependency test on the simulated results has been carried out by considering three different computational grid cells of 29,420, 58,727 and 118,204 respectively. A negligible difference is observed between the results obtained by 58,727 and 118,204 as shown in Fig. 3. Hence, the grid of 58,727 is chosen for all the simulation cases presented in the following sections. 


\subsection{Model validation}

Fig. 4 depicts the synthesis gas composition obtained from the experiment [15], kinetic and CFD models. The chemical kinetics used in the CFD model are same as those used in the kinetic model $[21,22]$. These kinetics are shown in Table 1.

A close examination in

Fig. 4 confirms that there is a discrepancy in predicting the compositions of $\mathrm{CO}$ and $\mathrm{H}_{2}$ between the two models. For instance, in the CFD model, the production of $\mathrm{CO}$ and $\mathrm{H}_{2}$ are less compared to those of the kinetic model and experiment, though the same set of chemical reactions were used in both the modelling approaches. The level of predicted discrepancy is understood due to the fact that the kinetic model assumed an equilibrium approach

particularly for the oxidation zone, while the CFD model is fully non-equilibrium which required a detailed specification of all the chemical reactions and species transports involved in the model.

In the literature different chemical kinetics are available for different reactions, it is therefore crucially important to investigate the suitable set of chemical kinetics that better aid the development of CFD model with a much improved predicted accuracy. The revised chemical kinetics examined are shown in Table 3. The key differences between the kinetic model and the revised chemical kinetics used in the CFD model are mainly with the values of the frequency factor and activation energy. Temperature exponent in the heterogeneous reactions is also included in the revised reactions. In addition, water shift gas reaction is included, and these revised chemical kinetics are used to further investigate the gasification processes through the CFD model.

Fig. 5 depicts the comparison of the simulated outlet composition of gases $\left(\mathrm{CO}, \mathrm{CO}_{2}, \mathrm{H}_{2}\right.$, $\mathrm{CH}_{4}$, and $\mathrm{N}_{2}$ ) with those obtained by the experiment and kinetic model [15, 21, 22], the first CFD and revised CFD models. These plots reveal that the simulated values of the outlet gas composition derived by the revised CFD model compare extremely well with those of the kinetic model prediction and experimental data. Hence, the new CFD modelling approach with the volatile break up is proved to be reliable.

\subsection{Effect of equivalence ratio}


Fig. 6 illustrates the temperature profile along the gasifier height in downdraft gasifier simulated at different equivalence ratio (ER) changing from 0.35 to 0.60 . As seen in both figures, when the value of ER increases, the oxidation temperature increases due to an increase in oxygen concentration in to the oxidation zone due to that char combustion and volatile combustion reactions (all are exothermic reactions) are triggered and result of that temperature increases. This is also proved from the contour plots of temperature at the various ER ratios. The predicted temperature was in good agreement with that of the previously published results in the literature.

However, a significant drop in the temperature is examined in the pyrolysis zone. Drying and pyrolysis zone are taking heat from the oxidation zone. Therefore, process is linked with the endothermic drying, pyrolysis zone, and exothermic oxidation zone. In the oxidation zone temperature increased and eventually becomes the highest due to the exothermic reactions occurring in this zone. In the reduction zone, mainly the endothermic reactions occur and, due to this, the temperature in the reduction zone drops.

In the gasification of biomass, equivalence ratio is one of the most important parameter used to predict the process performance and design of the gasifier. As seen in Fig. 7, the quality of gas obtained from the gasifier depends on the ER value. However, a relatively low value of the equivalence ratio may result in many problems, e.g. it may lead to a low heating value of gases produced with an excessive amount of char formation thus further resulting in an incomplete gasification. On the other side, a too large value of equivalence ratio may result in an excessive formation of products through a complete combustion process. A close examination in Fig. 7 further shows that methane mole fraction decreases with the equivalence ratio increases. However, in other side the mole fraction of carbon dioxide increases with the equivalence ratio due to combustion while mole fraction of both carbon monoxide and hydrogen decreases with increases with the equivalence ratio.

\subsection{Gas species distribution}

Fig. 8 depicts the mole fraction distributions of the product gases formed within the downdraft gasifier during gasification at $E R=0.35$. When the biomass fuel enters in the gasifier the volatile reaction takes place, resulting in the production of mainly $\mathrm{CO}, \mathrm{CO}_{2}, \mathrm{CH}_{4}$, $\mathrm{H}_{2}, \mathrm{H}_{2} \mathrm{O}$ and char. Char then further reacts with the gas species like $\mathrm{O}_{2}, \mathrm{H}_{2}$ and $\mathrm{CO}_{2}$ and forms the synthesis gas. However, oxygen related to all the reaction takes place in the 
oxidation zone, while the other reactions take place in the reduction zone. The concentrations of $\mathrm{CO}$ and $\mathrm{H}_{2}$ are more in the pyrolysis zone because of the volatile release gases after devolatilization. The devolatilization takes place in the pyrolysis zone. When the release gases $\mathrm{CO}$ and $\mathrm{H}_{2}$ reach in the oxidation zone, they react with the oxygen and subsequently convert into $\mathrm{CO}_{2}$ and $\mathrm{H}_{2} \mathrm{O}$. But, not all the $\mathrm{CO}$ and $\mathrm{H}_{2}$ are converted into $\mathrm{CO}_{2}$ and $\mathrm{H}_{2} \mathrm{O}$ due to the control supply of oxygen. However, $\mathrm{CO}_{2}$ and $\mathrm{H}_{2} \mathrm{O}$ further react with char and produce $\mathrm{CO}$ and $\mathrm{H}_{2}$ in the reduction zone. It is further observed in the contour plots that the hydrogen and carbon monoxide have higher composition than the other gas compositions. The hydrogen is mainly produced from the water gas shift and methane steam reforming reactions.

\subsection{Volatile matter decomposition}

Fig. 9 represents the decomposition of volatile matter concentration along the downdraft gasifier height at $\mathrm{ER}=0.35$ When biomass enters from the top of the gasifier, due to the heat supplied by the oxidation zone it breaks down to volatile, char and tar. Further, the volatile content breaks into various gases. A close examination in Fig. 9 shows that the volatile matter from biomass decomposes along with the gasifier height. Volatile matter decomposition mostly takes place in the pyrolysis zone. Fig. 9 clearly shows that all the volatile matter decomposed at the distance between $0.5 \mathrm{~m}$ to the top $(0.96 \mathrm{~m})$ the gasifier, which is the pyrolysis zone.

\subsection{Oxidation zone reactions}

Oxidation zone reaction plays an important role for gasification of biomass in downdraft gasifier. Because all the species release from the volatile and char comes first time, get contact with the air in the oxidation zone. Fig. 10 shows the rate of reactions for those that take place with oxygen in the oxidation zone. The highest rate of reaction is for combustion of carbon monoxide, which is exothermic reaction followed by the H-combustion and methane combustion. All the oxidation zone reactions taking place in the gasifier at height between $0.3 \mathrm{~m}$ to $0.59 \mathrm{~m}$.

\subsection{Reduction zone reactions}

Fig. 11 shows the reaction rates for the reduction zone reactions in the gasifier. All the reduction zone reactions taking place in the reduction zone (0 to $0.26 \mathrm{~m})$. Methane production reaction has the fastest reaction rate followed by the water gas reaction and Boudouard 
reaction, respectively. Boudouard reaction has a slow reaction rate because $\mathrm{CO}_{2}$ molecule is very stable thus the result of that rate of reaction is very slow. The rate of reaction of the Boudouard reaction may be increased by using a suitable catalyst. Further, the reduction zone reactions also occur in the oxidation zone because the temperature in that zone is high and consequently, the endothermic reactions are trigger in this zone, as clearly seen in Fig. 11, height from $0.34 \mathrm{~m}$ to $0.46 \mathrm{~m}$.

\subsection{Comparison of different feedstocks}

Fig. 12 represents a comparison of the outlet gas composition of various product gases from the gasification of various biomass feedstocks (barley screenings, barley dust, wood chip and rubber wood) [24]. The gasifier design and operating conditions and the chemical kinetics used in the previous sections remain the same for all the four feedstocks but the equivalence ratio is fixed to 0.35 . A close examination of this figure reveals the following salient features:

1. The highest concentration of carbon monoxide at the gasifier outlet observed for the barley screenings and rubber wood and followed by barley dust and wood chips.

2. The hydrogen mole fraction is highest for rubber wood and barley screenings but comparatively, it is low for barley dust and wood chips.

3. The mole fraction of carbon dioxide is higher for barley dust and wood chips but it is lower for rubber wood and barley screenings.

The above facts are due to the variation in the ultimate and proximate analysis for the different biomass feedstocks. For example, rubber wood sawdust contains heights volatile matter and $\mathrm{H}$ contents than the barley dust and wood chips. Due to that the release of volatile gases is predicted to be more and therefore, resulting in the formation of more carbon monoxide and hydrogen compared to those of the barley dust and wood chips.

\section{Conclusions}

A numerical model was developed to simulate the gasification process of rubber wood in a downdraft gasifier using the Eulerian-Lagrange computational fluid dynamics (CFD) model. Initially, the chemical kinetics used in the CFD model was same as those used in the kinetic model. However, the results from the CFD model showed some variation in the composition of synthesis gases. Therefore, the chemical kinetic in the CFD model was revised in terms of the frequency factor and the activation energy and also included an extra water shift gas 
reaction. The simulated results with the revised chemistry revealed that the outlet gas composition of the different species was closer to the kinetic model's results. Further, the validated CFD model was used to investigate the effect of equivalence ratio on the outlet gas composition and gasifier temperature. Furthermore, different biomass feedstocks were tested for the gasification process and it was concluded that the rubber wood feedstock produced more synthesis gas compared to the other feedstocks. The present modelling approach is thus showing a promising way to simulate the biomass gasification processes in downdraft gasifier.

\section{Acknowledgement}

We gratefully acknowledge the Innovate UK (132362, TS/N011686/1) for their financial support. The second author (M. C. Paul) also acknowledges his RAEng/The Leverhulme Trust Senior Research Fellowship support (LTSRF1718\14\45).

\section{References}

[1] S. Jarungthammachote, A. Dutta, Thermodynamic equilibrium model and second law analysis of a downdraft waste gasifier, Energy 32(9) (2007) 1660-1669.

[2] Z. A. Zainal, R. Ali, C. H. Lean, K. N. Seetharamu, Prediction of performance of a downdraft gasifier using equilibrium modeling for different biomass materials, Energy Conversion and Management 42(12) (2001) 1499-1515.

[3] A. K. Sharma, Equilibrium modeling of global reduction reactions for a downdraft (biomass) gasifier, Energy Conversion and Management 49(4) (2008) 832-842.

[4] A. Melgar, J. F. Pe'rez, H. Laget, A. Horillo, Thermochemical equilibrium modelling of a gasifying process, Energy Conversion and Management 48(1) (2007) 59-67.

[5] H. J. Huang, S. Ramaswamy, Modeling Biomass Gasification Using Thermodynamic Equilibrium Approach, Appl Biochem Biotech 154(1-3) (2009) 193-204.

[6] Y. Wang, C. M. Kinoshita, Kinetic model of biomass gasification, Solar Energy 51(1) (1993) 19-25.

[7] C. D. Blasi, Dynamic behaviour of stratified downdraft gasifiers, Chemical Engineering Science 55 (2000) 2931-2944.

[8] S. A. Maria, L. Jun, M. C. Paul, Assessing biomass steam gasification technologies using a multi-purpose model, Energy Conversion and Management 129 (2016) 216-226.

[9] C. Chen, M. Horio, T. Kojima, Numerical simulation of entrained flow coal gasifiers. Part 
I: modeling of coal gasification in an entrained flow gasifier, Chemical Engineering Science 55(18) (2000) 3861-3874.

[10] L. Gerun, M. Paraschiv, R. Vîjeu, J. Bellettre, M. Tazerout, B. Gøbel, U. Henriksen, Numerical investigation of the partial oxidation in a two-stage downdraft gasifier, Fuel 87(7) (2008) 1383-1393.

[11] M. Aziz, D. Budianto, T. Oda, Computational Fluid Dynamic Analysis of Co-Firing of Palm Kernel Shell and Coal, Energies 9(3) (2016) 137.

[12] A. Go'mez-Barea , B. Leckner, Modeling of biomass gasification in fluidized bed, Progress in Energy and Combustion Science 36(4) (2010) 444-509.

[13] I. Janajreh, M. A. Shrah, Numerical and experimental investigation of downdraft gasification of wood chips, Energy Conversion and Management 65 (2013) 783-792.

[14] P. Nakod, Modeling and validation of oxy-fired and air-fired entrained flow gasifiers, International Journal of Chemical and Physical Sciences 2 (6) (2013) 2319-6602

[15] T. H. Jayah, L. Aye, R. J. Fuller, D.F. Stewart, Computer simulation of a downdraft wood gasifier for tea drying, Biomass and Bioenergy 25(4) (2003) 459-469.

[16] F. L. Dryer, I. Glassman, High-temperature oxidation of $\mathrm{CO}$ and $\mathrm{CH} 4$, Symposium (International) on Combustion 14(1) (1973) 987-1003.

[17] J. B. Howard, G. C. Williams, D.H. Fine, Kinetics of carbon monoxide oxidation in postflame gases, Symposium (International) on Combustion 14(1) (1973) 975-986.

[18] R. A. Yetter, F. L. Dryer, H. Rabitz, Complications of one-step kinetics for moist CO oxidation, Symposium (International) on Combustion 21(1) (1988) 749-760.

[19] U. Kumar, A. M. Salem, M. C. Paul, Investigating the thermochemical conversion of biomass in a downdraft gasifier with a volatile break-up approach, Energy Procedia 142 (2017) 822-828.

[20] M. Bissett, M. Syamlal, METC Gasifier Advanced Simulation (MGAS) Model, National Technical Information Services, 1992.

[21] M. C. Paul. A. M. Salem, Advanced Kinetic Modelling Of Biomass Gasification Based On Optimum Height Of The Reduction Zone, International Journal of Advances in Science Engineering and Technology 4(3) (2016) 182-185.

[22] A. M. Salem, M. C. Paul, An integrated kinetic model for downdraft gasifier based on a novel approach that optimises the reduction zone of gasifier, Biomass and Bioenergy 109 (2018) 172-181.

[23] ANSYS 15 Fluent Theory Guide, Canonsburg, PA 15317, 2013. 
[24] A. M. Salem, U. Kumar, A. N. Izaharuddin, H. Dhami, T. Sutardi, M.C. Paul, Advanced Numerical Methods for the Assessment of Integrated Gasification and CHP Generation Technologies, Coal and Biomass Gasification, Springer2018, pp. 307-330, ISBN: 978-98110-7334-2.

[25] J. Xie, W. Zhong, B. Jin, Y. Shao, H. Liu, Simulation on gasification of forestry residues in fluidized beds by Eulerian-Lagrangian approach, Bioresource Technology 121 (2012) 3646. 


\section{Nomenclature}

$A_{p} \quad$ Surface area of the particle $\left(\mathrm{m}^{2}\right)$

$c_{p} \quad$ Heat capacity of the particle $(\mathrm{J} / \mathrm{kg} . \mathrm{K})$

$D_{i, m} \quad$ Mass diffusion coefficient for species $\mathrm{i}$ in the mixture

$D_{p} \quad$ Particle diameter $(\mu \mathrm{m})$

$D_{T, i} \quad$ Thermal diffusion coefficient for species i

$D_{t} \quad$ Turbulent diffusivity

$f_{h} \quad$ Particle absorbs fraction of heat

$F_{i} \quad$ External body forces

$g_{i} \quad$ Gravitational body forces

$G_{b} \quad$ Turbulence kinetic energy due to buoyancy

$G_{k} \quad$ Turbulence kinetic energy due to the mean velocity gradients

$h \quad$ Convective heat transfer coefficient $\left(\mathrm{W} / \mathrm{m}^{2} . \mathrm{K}\right)$

$h_{f g} \quad$ Latent heat $(\mathrm{J} / \mathrm{kg})$

$H_{\text {reac }}$ Heat released by the surface reaction

I Unit tensor

$J_{i} \quad$ Diffusion flux of species $\mathrm{i}$

$m_{a} \quad$ Mass of ash particle $(\mathrm{kg})$

$m_{p, 0} \quad$ Initial particle mass at injection

$m_{p} \quad$ Mass of the particle $(\mathrm{kg})$

$m_{v}(t)$ Volatile yield up to time $\mathrm{t}$

$\frac{d m_{p}}{d t} \quad$ Rate of evaporation $(\mathrm{kg} / \mathrm{s})$

Re Reynolds number

$R_{i} \quad$ Net rate of production of species i by chemical reaction

$S_{i} \quad$ Mass added to the continuous phase from the dispersed phase

$S_{k} \quad$ Source terms for the kinetic energy

$S_{\epsilon} \quad$ Source terms for rate of dissipation

$S c_{t} \quad$ Schmidt number for turbulent flow

$T \quad$ Local temperature of the continuous phase (K)

$T_{p} \quad$ Temperature of particle (K) 
$T_{R} \quad$ Temperature of radiation $(\mathrm{K})$

$u \quad$ Fluid velocity $(\mathrm{m} / \mathrm{s})$

$\overrightarrow{u_{p}} \quad$ Particle velocity $(\mathrm{m} / \mathrm{s})$

$x_{i} \quad$ Number of mole species

$Y_{i} \quad$ Mass fraction of species $\mathrm{i}$

$Y_{M} \quad$ Contribution of the fluctuating dilatation in compressible turbulence to the overall dissipation rate

\section{Greek letters}

$\rho \quad$ Fluid density $\left(\mathrm{kg} / \mathrm{m}^{3}\right)$

$\tau_{i, j} \quad$ Stress tensor

$\mu \quad$ Molecular viscosity

$\sigma_{k} \quad$ Turbulent Prandtl numbers for $\mathrm{k}$

$\sigma_{\varepsilon} \quad$ Turbulent Prandtl numbers for $\epsilon$

$\mu_{t} \quad$ Turbulent viscosity

$\rho_{p} \quad$ Density of the particle

$\epsilon_{p} \quad$ Particle emissivity

$\sigma \quad$ Stefan Boltzmann constant $\left(5.67 \times 10^{-8} \frac{\mathrm{kg}}{\mathrm{s}^{-3} \mathrm{~K}^{-4}}\right)$

$\alpha_{1}, \alpha_{2} \quad$ Yield factors 
Table 1. Chemical reactions used in the oxidation and reduction zones

Oxidation zone reactions

\begin{tabular}{lccccc}
\hline & Reactions & $A$ & $E / R$ & $T$ (exponent) & Reference \\
\hline $\mathrm{R} 1$ & $\mathrm{C}+0.5 \mathrm{O}_{2} \rightarrow \mathrm{CO}$ & 0.554 & 10824 & 0 & {$[3]$} \\
$\mathrm{R} 2$ & $\mathrm{CO}+0.5 \mathrm{O}_{2} \rightarrow \mathrm{CO}_{2}$ & $1.3 \mathrm{e}+8$ & 15106 & 0 & {$[3]$} \\
$\mathrm{R} 3$ & $\mathrm{H}_{2}+0.5 \mathrm{O}_{2} \rightarrow \mathrm{H}_{2} \mathrm{O}$ & $1.6 \mathrm{e}+09$ & 3420 & 1.5 & {$[3]$} \\
$\mathrm{R} 4$ & $\mathrm{CH}_{4}+1.5 \mathrm{O}_{2} \rightarrow \mathrm{CO}+2 \mathrm{H}_{2} \mathrm{O}$ & $1.585 \mathrm{e}+09$ & 24157 & 0 & {$[22]$} \\
\hline
\end{tabular}

\section{Reduction zone reactions}

\begin{tabular}{cccccc}
\hline & Reactions & $\boldsymbol{A}$ & $\boldsymbol{E}(\mathbf{k J} / \mathbf{m o l})$ & $\boldsymbol{T}$ (exponent) & Reference \\
\hline $\mathrm{R} 5$ & $\mathrm{C}+\mathrm{CO}_{2} \rightarrow 2 \mathrm{CO}$ & 36.16 & 77.39 & 0 & {$[6]$} \\
$\mathrm{R} 6$ & $\mathrm{C}+\mathrm{H}_{2} \mathrm{O} \rightarrow \mathrm{CO}+\mathrm{H}_{2}$ & $1.517 \mathrm{e}+4$ & 121.62 & 0 & {$[6]$} \\
$\mathrm{R} 7$ & $\mathrm{C}+2 \mathrm{H}_{2} \rightarrow \mathrm{CH}_{4}$ & $4.189 \mathrm{e}-03$ & 19.21 & 0 & {$[6]$} \\
$\mathrm{R} 8$ & $\mathrm{CH}_{4}+\mathrm{H}_{2} \mathrm{O} \rightarrow \mathrm{CO}+3 \mathrm{H}_{2}$ & $7.301 \mathrm{e}-2$ & 36.15 & 0 & {$[6]$} \\
\hline
\end{tabular}

Table 2. Characterization of rubber wood [15]

\begin{tabular}{lclc}
\hline Ultimate analysis (wt\% dry basis) & Proximate analysis (wt \% dry basis) & \\
\hline C & 50.6 & Volatile matter & 81.1 \\
H & 6.5 & Fixed carbon & 19.2 \\
O & 42 & Ash & 0.7 \\
N & 0.2 & Moisture content (wt \% wet basis) & 18.5 \\
S & 0 & Higher heating value $(\mathrm{kJ} / \mathrm{kg})$ & 20540 \\
\hline
\end{tabular}


Table 3. Revised reactions used in the oxidation and reduction zones

Oxidation zone reactions

\begin{tabular}{lccccc}
\hline & Reactions & $A$ & $E(\mathrm{~kJ} / \mathrm{mol})$ & $T$ (exponent) & Reference \\
\hline $\mathrm{R} 1$ & $2 \mathrm{C}+\mathrm{O}_{2} \rightarrow 2 \mathrm{CO}$ & 147000 & 112.99 & 1 & {$[25]$} \\
$\mathrm{R} 2$ & $\mathrm{CO}+0.5 \mathrm{O}_{2} \rightarrow \mathrm{CO}_{2}$ & $1.0 \mathrm{e}+10$ & 126 & 0 & {$[12]$} \\
$\mathrm{R} 3$ & $2 \mathrm{H}_{2}+0.5 \mathrm{O}_{2} \rightarrow 2 \mathrm{H}_{2} \mathrm{O}$ & $2.2 \mathrm{e}+09$ & 109 & 0 & {$[12]$} \\
$\mathrm{R} 4$ & $\mathrm{CH}_{4}+1.5 \mathrm{O}_{2} \rightarrow \mathrm{CO}+2 \mathrm{H}_{2} \mathrm{O}$ & $4.4 \mathrm{e}+11$ & 126 & 0 & {$[12]$} \\
\hline
\end{tabular}

Reduction zone reactions

\begin{tabular}{cccccc}
\hline & Reactions & $A$ & $E(\mathrm{~kJ} / \mathrm{mol})$ & $T$ (exponent) & Reference \\
\hline $\mathrm{R} 5$ & $\mathrm{C}+\mathrm{CO}_{2} \rightarrow 2 \mathrm{CO}$ & 8.268 & 188.2 & 1 & {$[25]$} \\
$\mathrm{R} 6$ & $\mathrm{C}+\mathrm{H}_{2} \mathrm{O} \rightarrow \mathrm{CO}+\mathrm{H}_{2}$ & 8.268 & 188.2 & 1 & {$[25]$} \\
$\mathrm{R} 7$ & $0.5 \mathrm{C}+\mathrm{H}_{2} \rightarrow 0.5 \mathrm{CH}_{4}$ & $8.8894 \mathrm{e}-06$ & 67.16 & 1 & {$[25]$} \\
$\mathrm{R} 8$ & $\mathrm{CH}_{4}+\mathrm{H}_{2} \mathrm{O} \rightarrow \mathrm{CO}+3 \mathrm{H}_{2}$ & $3 \mathrm{e}+08$ & 125 & 0 & {$[12]$} \\
$\mathrm{R} 9$ & $\mathrm{CO}+\mathrm{H}_{2} \mathrm{O} \rightarrow \mathrm{CO}_{2}+\mathrm{H}_{2}$ & $2.35 \mathrm{e}+10$ & 288 & 0 & {$[14]$} \\
$\mathrm{R} 10$ & $\mathrm{CO}_{2}+\mathrm{H}_{2} \rightarrow \mathrm{CO}+\mathrm{H}_{2} \mathrm{O}$ & $1.785 \mathrm{e}+12$ & 326 & 0 & {$[14]$}
\end{tabular}




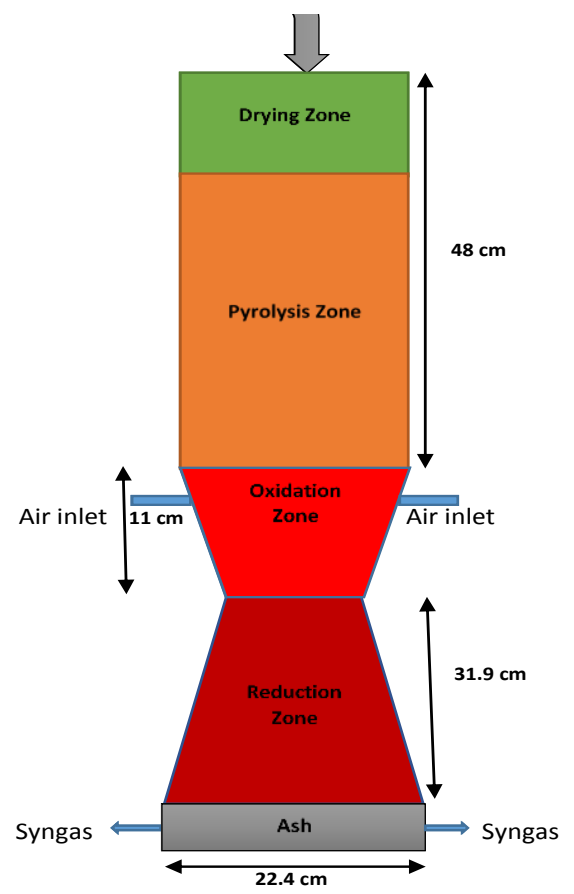

Fig. 1: Schematic view of the downdraft gasifier. 


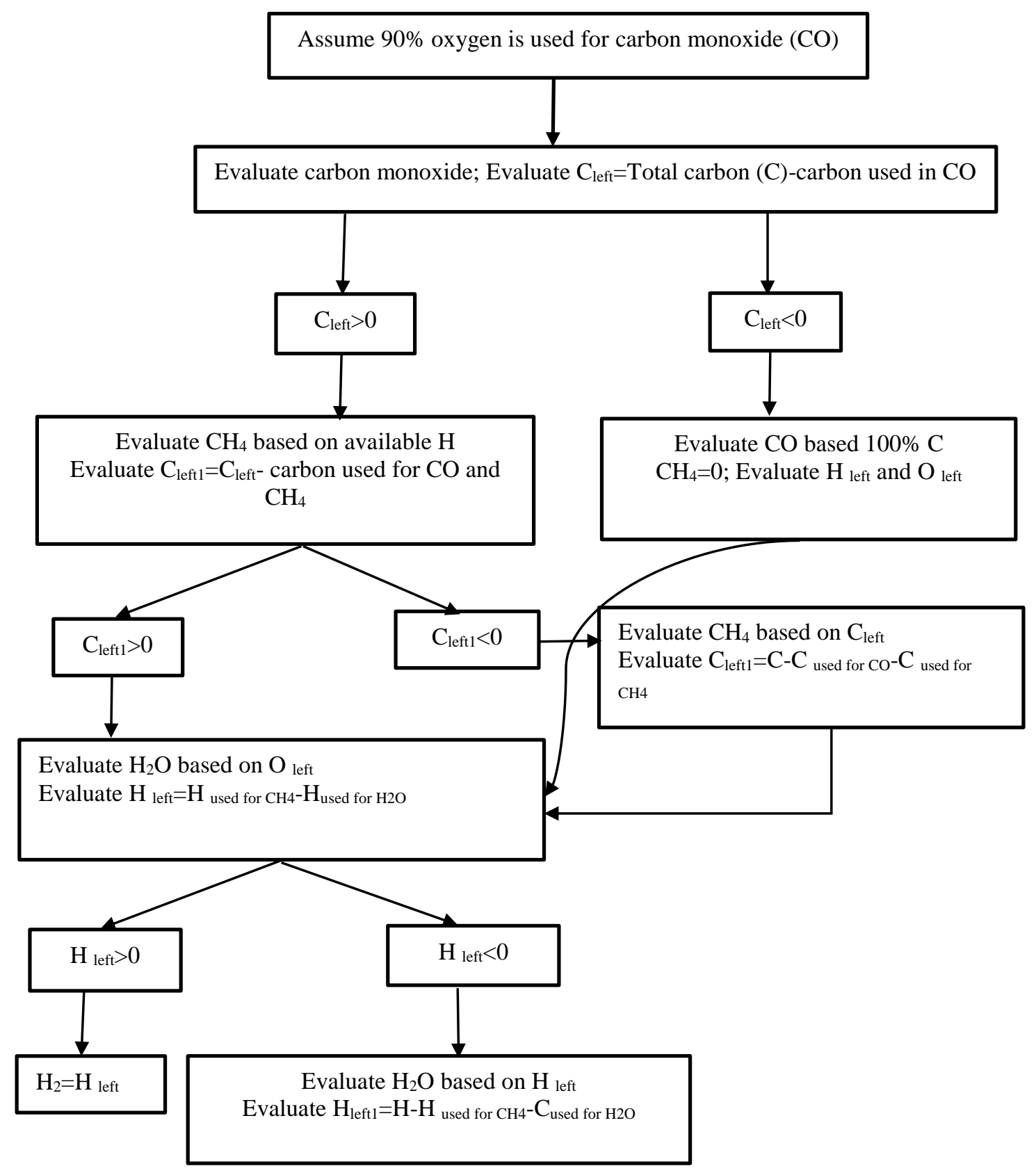

Fig. 2 Scheme adopted to calculate the stoichiometric coefficients from biomass 


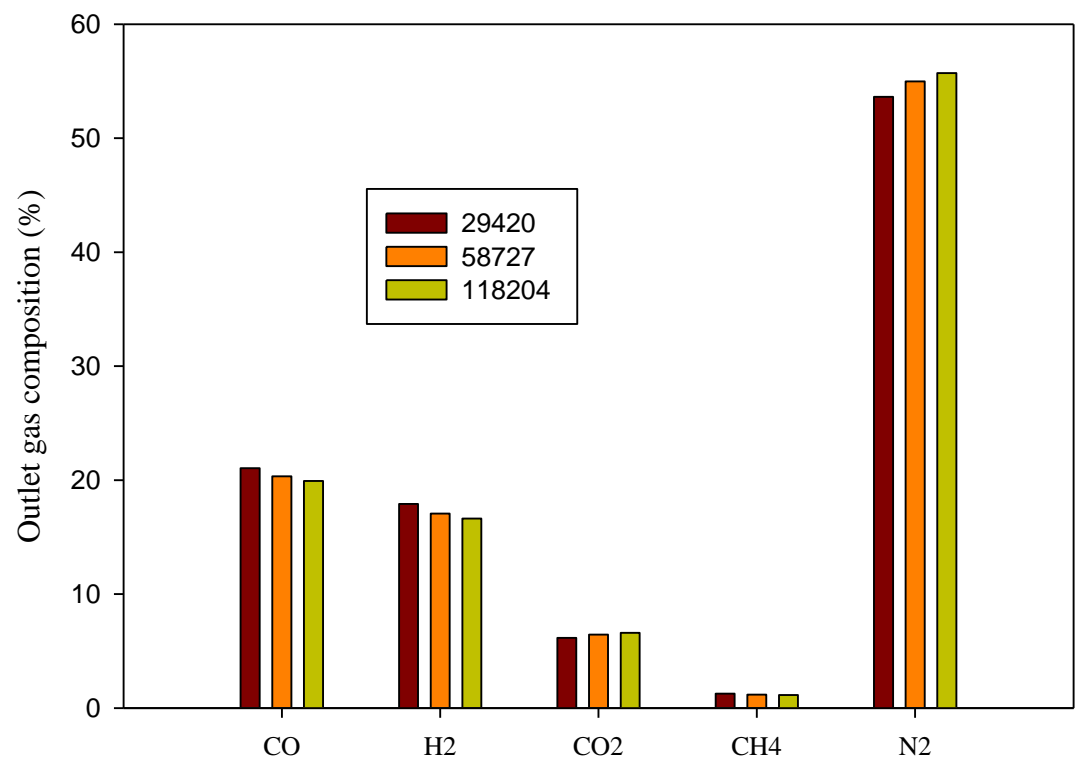

Fig. 3 Gas composition at the gasifier outlet for different mesh sizes

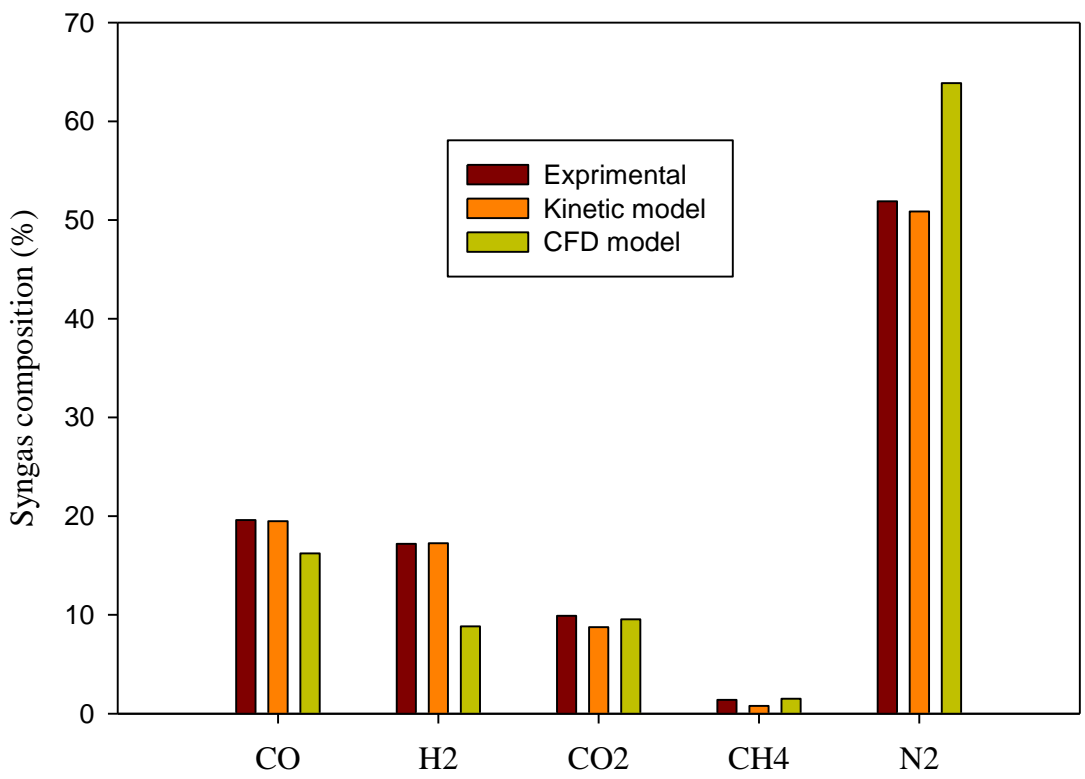

Fig. 4. Synthesis gas composition comparison (dry basis). 


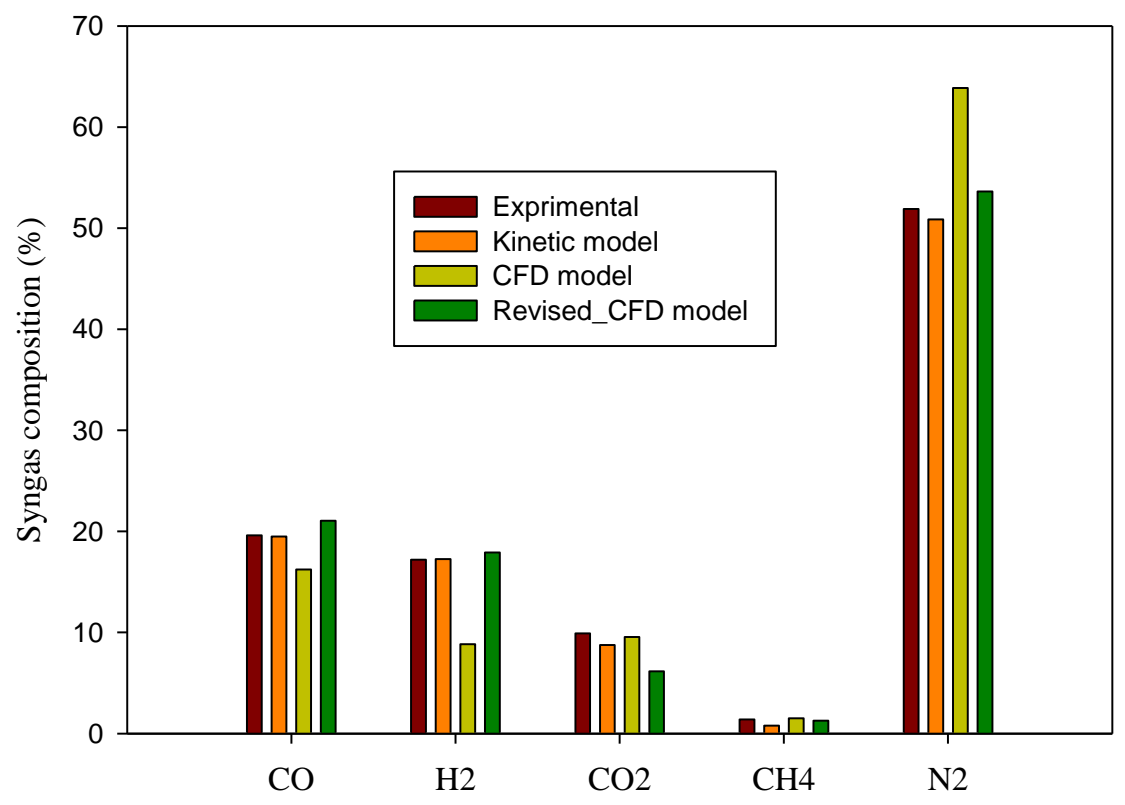

Fig. 5. Comparison between the CFD, revised CFD and kinetic model predicted results. 


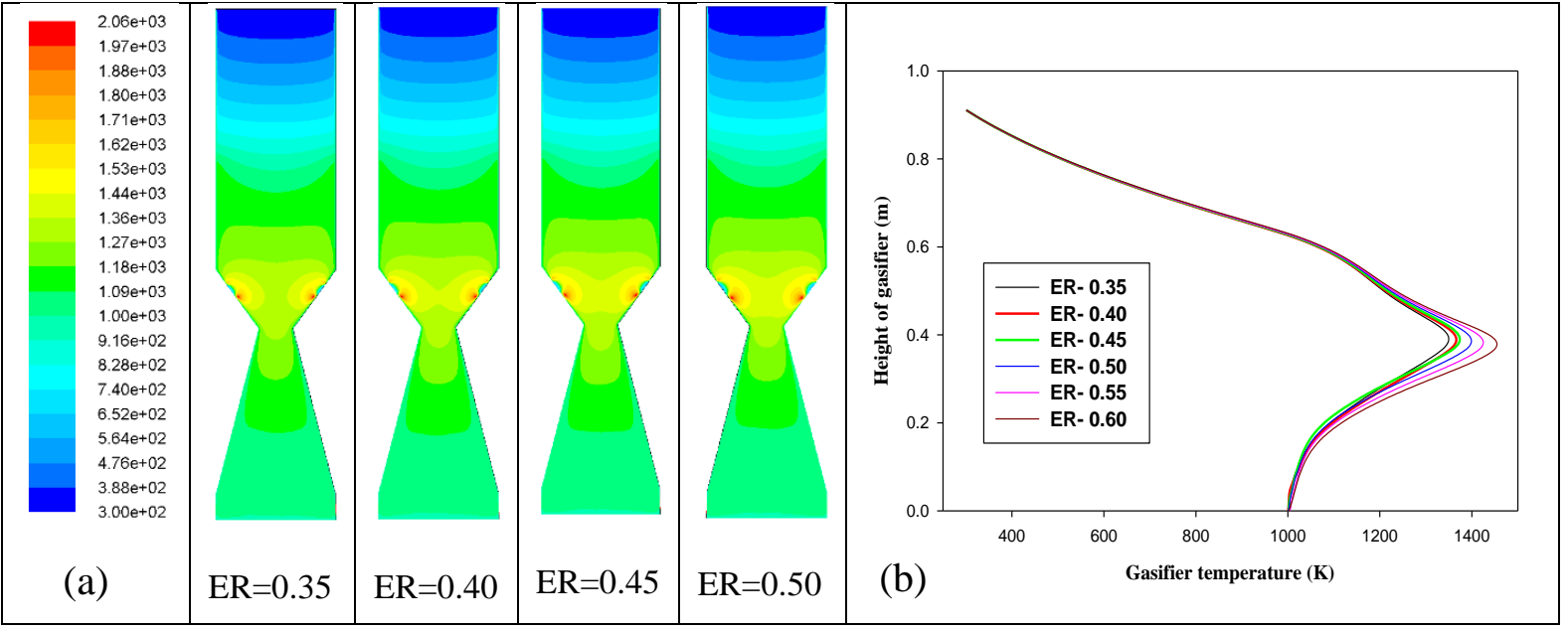

Fig. 6. Gasifier temperature contour and (b) profiles at different ER along the height of gasifier 


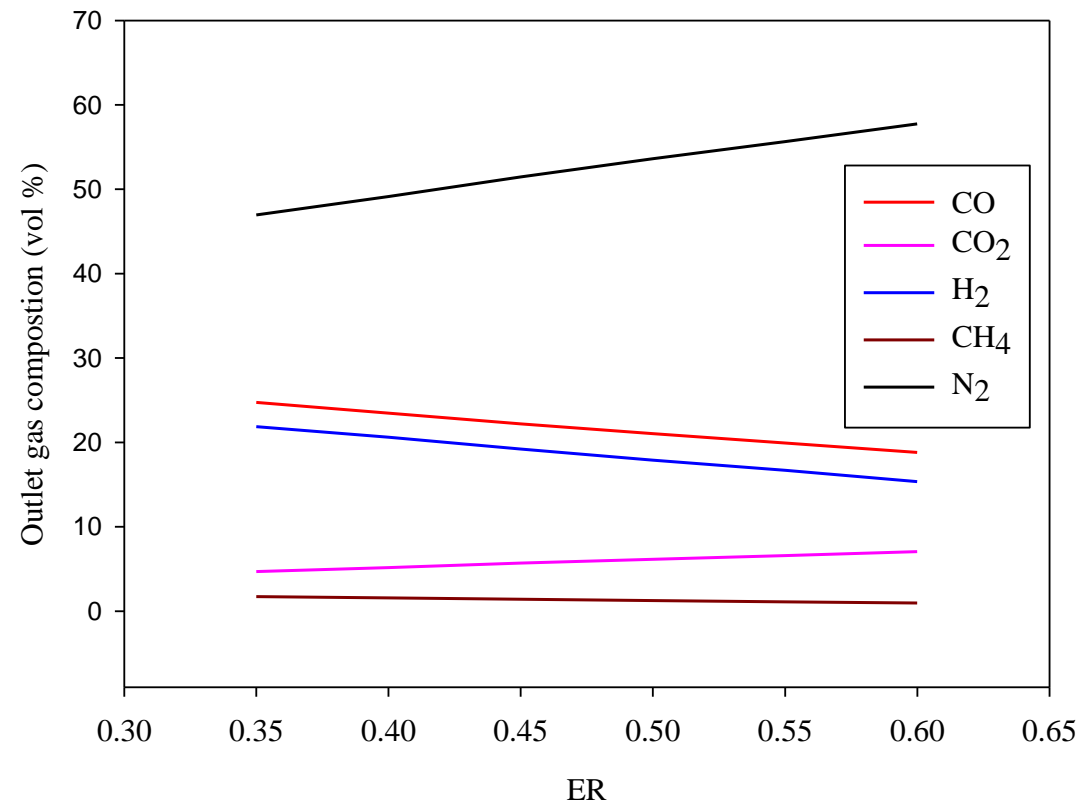

Fig. 7. Outlet gas composition in gasifier at different equivalence ratio 

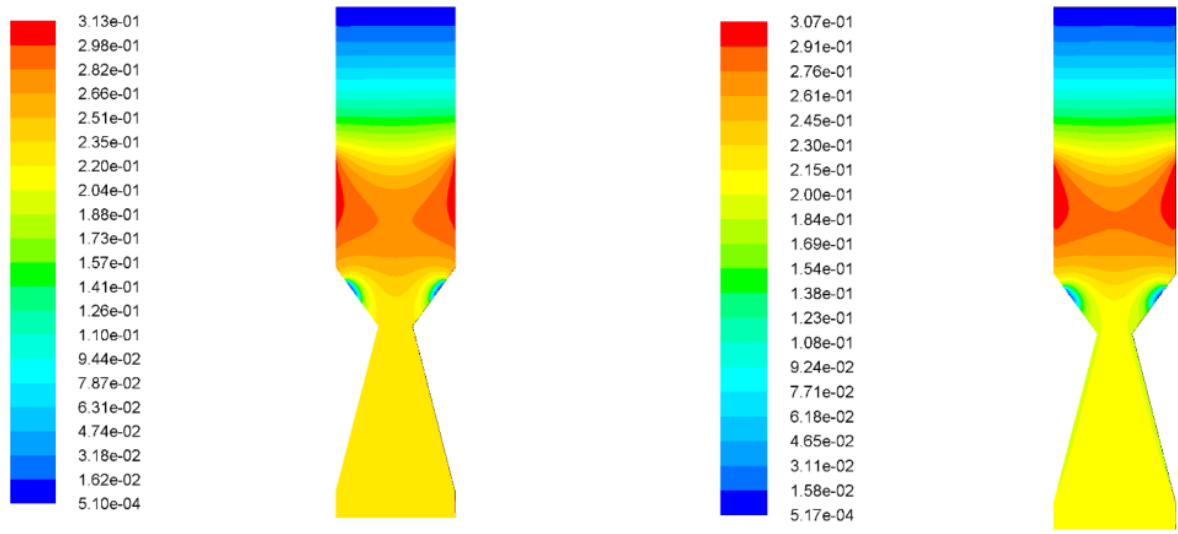

$\mathrm{CO}$

$\mathrm{H}_{2}$
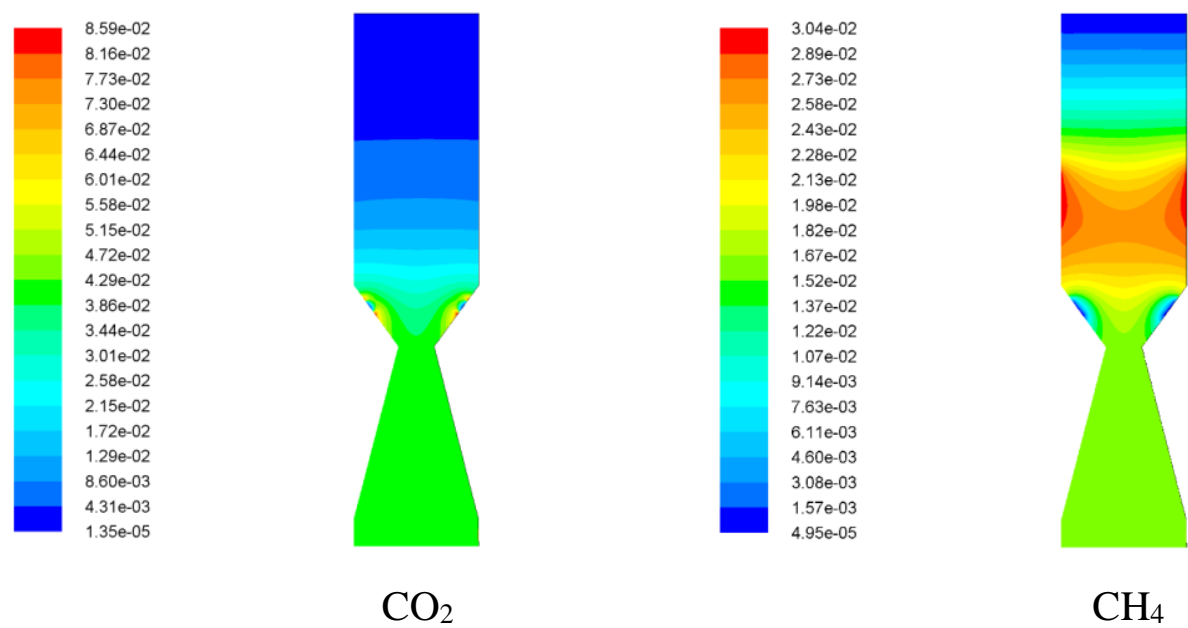

$\mathrm{CH}_{4}$
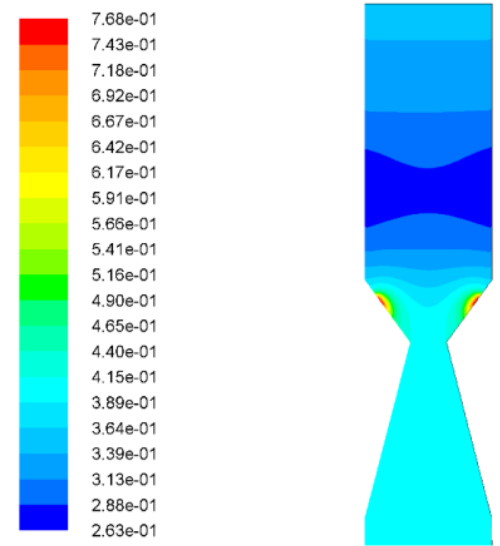

$\mathrm{N}_{2}$

Fig. 8. Contour plots of different gas compositions $(\mathrm{ER}=0.35)$. 


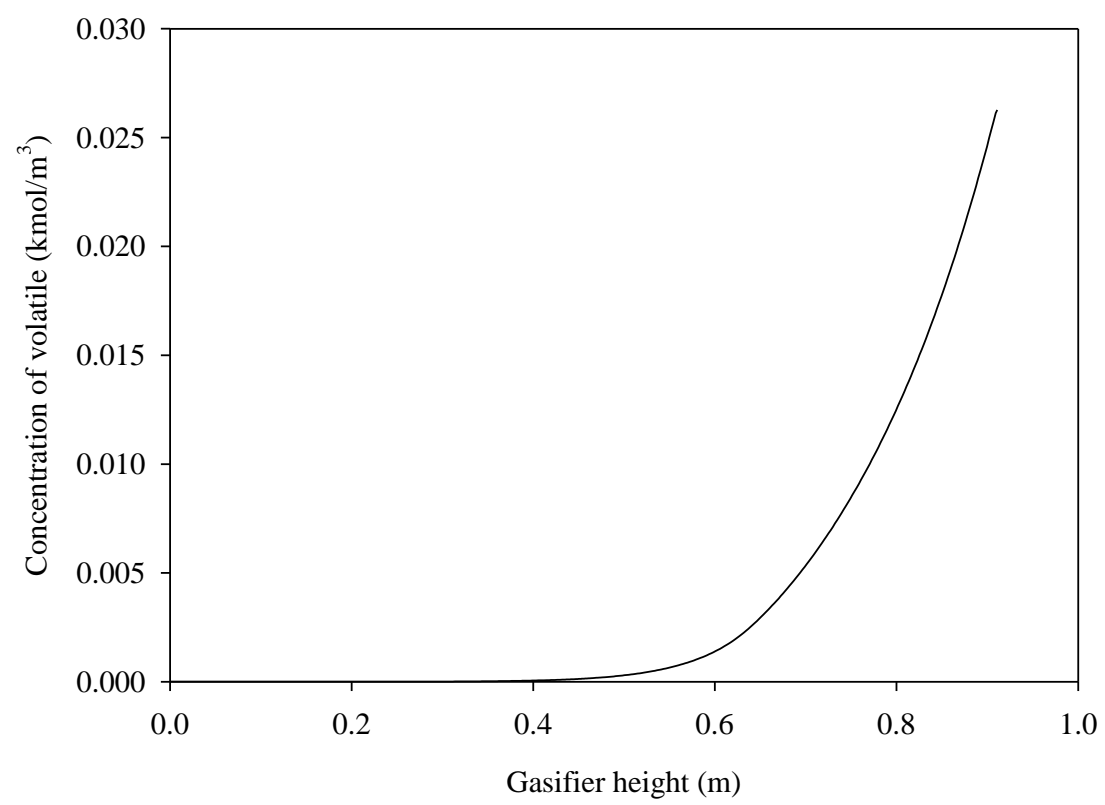

Fig. 9 Volatile decomposition concentration profile along with the gasifier height at $E R=0.35$

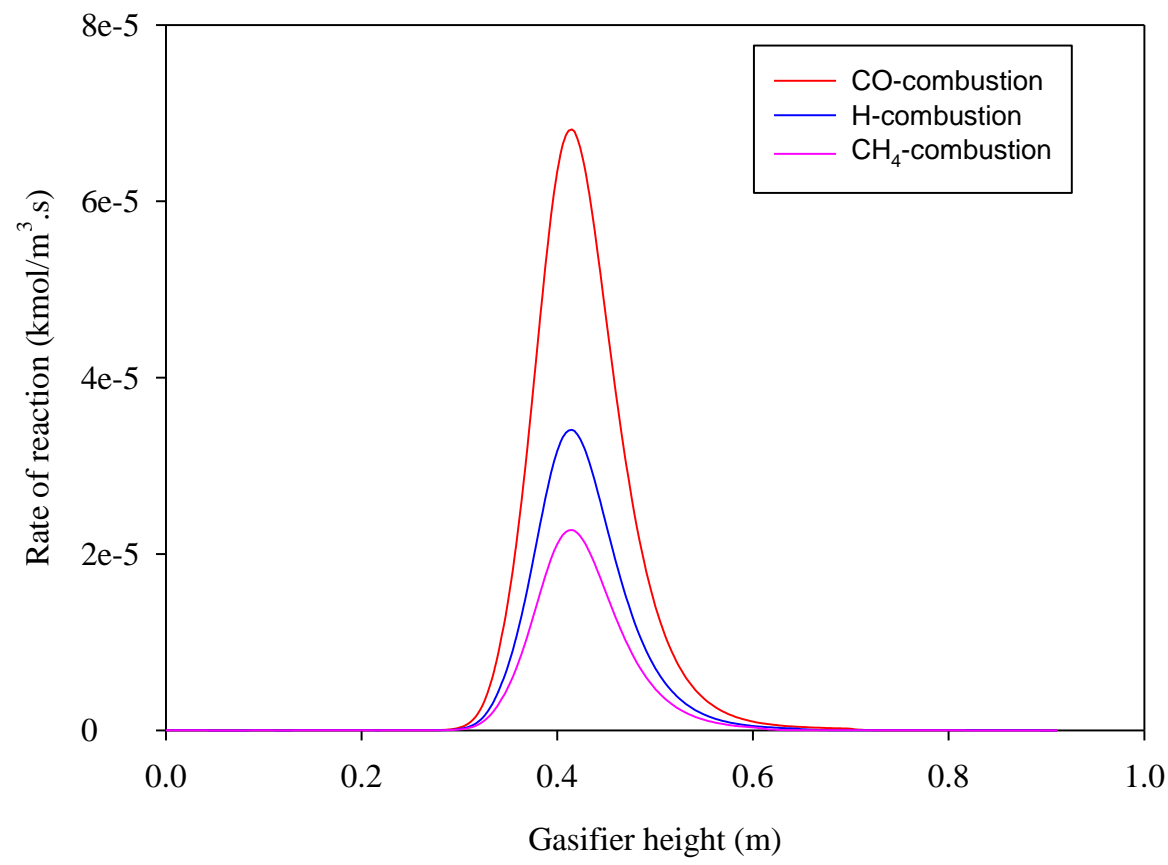

Fig. 10 Rate of reaction profile for oxidation zone reactions along with gasifier height 


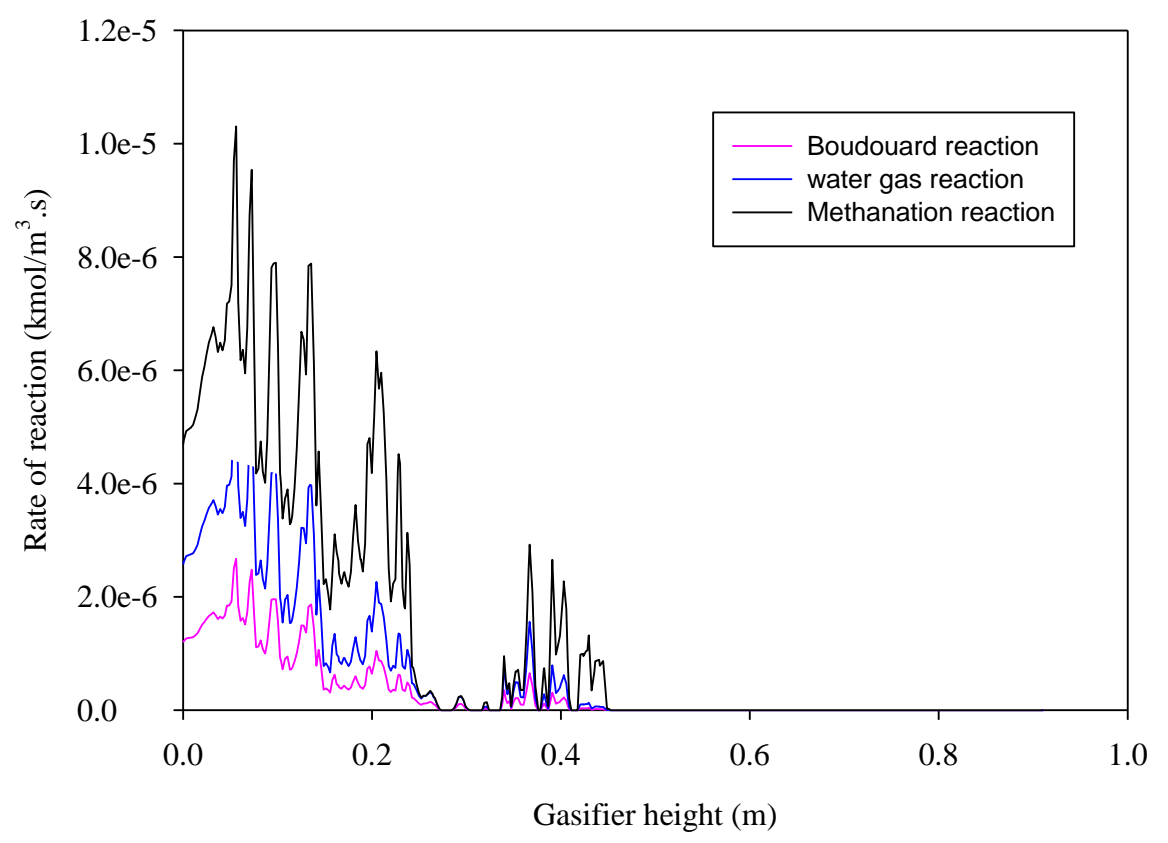

Fig. 11 Rate of reaction profile for reduction zone reactions along with gasifier height 


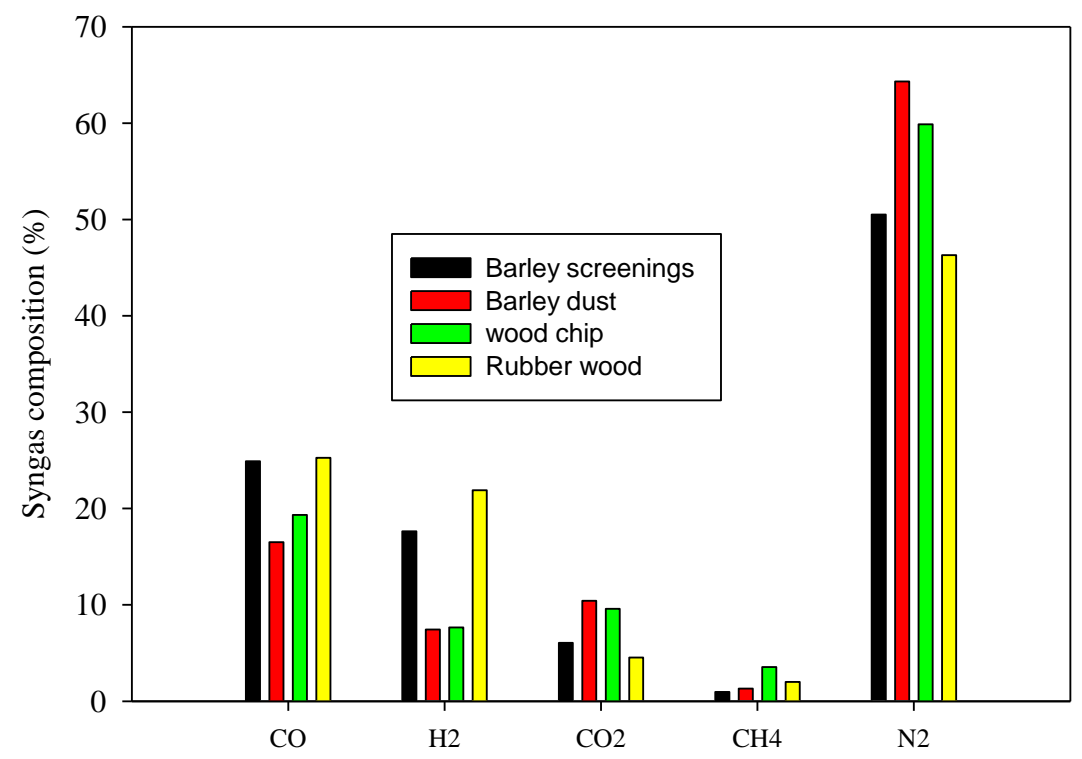

Fig. 12. Comparison between the outlet gas compositions for different biomass feedstocks at $\mathrm{ER}=0.35$ 